\title{
Article \\ Expert Opinions on the Intranet-Based Security System in Industrial Electrical Switchboards
}

\author{
Siwanatthakul Chaiyason and Kittipol Wisaeng *(D) \\ Mahasarakham Business School, Mahasarakham University, Mahasarakham 44150, Thailand; \\ 62010990007@msu.ac.th \\ * Correspondence: kittipol.w@acc.msu.ac.th
}

Citation: Chaiyason, S.; Wisaeng, K. Expert Opinions on the Intranet-Based Security System in Industrial Electrical Switchboards. Appl. Syst. Innov. 2021, 4, 83. https:// doi.org/10.3390/asi4040083

Academic Editor: Claudio Zunino

Received: 25 September 2021

Accepted: 25 October 2021

Published: 27 October 2021

Publisher's Note: MDPI stays neutral with regard to jurisdictional claims in published maps and institutional affiliations.

Copyright: (c) 2021 by the authors. Licensee MDPI, Basel, Switzerland. This article is an open access article distributed under the terms and conditions of the Creative Commons Attribution (CC BY) license (https:// creativecommons.org/licenses/by/ $4.0 /)$.

\begin{abstract}
The management and operation of an electrical switchboard originally was processed by an inspector so only tangible malfunctions could be identified while other intangible ones that can cause severe damages to the switchboard were overlooked. To solve this serious deprivation, this investigation, therefore, implemented an intranet sensors system in the electrical switchboard to create a new channel of communication via smart devices to operate and access it remotely, which will eventually lead to increased safety and efficiency of managing electrical switchboards, as well as manufacturing reliability and stability. All these will also increase competitiveness in business. The findings of this research indicate that the application could solve the deprivation by signaling all security malfunctions, both tangible and intangible, remotely via smartphones and laptops in the real-time operating system, which helps reduce severe damages to the switchboard, on-site inspection, and loss of service time to fix malfunctions and human and related risks, as well as increase manufacturing reliability and stability of the operation. The implemented intranet sensors system was also compatible with the current existing security system. This increased security, therefore, verifies the efficiency and business competitiveness of the intranet sensors system.
\end{abstract}

Keywords: intranet-based sensor system and interconnectivity; industrial powerline switchboard; power usage efficiency; ethernet-based pyrosensor; internet connectivity

\section{Introduction}

Modern design and development of the electrical system are in high demand of hardware and software security, overall system reliability, and stability, in order to efficiently create employee trust. This harbors business competitive advantage when employees do not feel the nervousness of industrial system failures or disruption. The advantages of an internet-based system indicate that it can be used to create an intranet system that can control electric circuits throughout the building. It can be also be designed to receive, display, and gather information to help create company policies. Prior technologies used in current industrial powerlines are still in use and demonstrate detrimental effects to be solved. Current industrial powerline switchboards in the manufacturing facility have been encountering incompatibility issues with modern equipment equipped in modern technology infrastructure. These unsolved, detrimental effects have caused arduous and demanding burdens of device management due to equipment malfunction, lack of reliability, and massive loss in electrical energy. Other co-existing detriments are that employees were not well-acquainted with modern technologies. This can lead to a slower time to operate new devices efficiently and staggering the time to appreciate what modern technologies need to offer at hand. The information available on modern devices can yield updates of power utilization throughout the manufacturing facility, from every point of device installment. Output information from every single point can display viable data indicating in which direction the organization should proceed.

The intranet power management system and interconnectivities can be effectively implemented to overall electrical power systems or electrical switchboards in the manufac- 
turing facility. Installments of the introduced system are able to reduce power usage within the facility. Hence, production costs in the future can be lowered due to the elimination of excessive usage. Power usage of the facility can be monitored in real time, and human errors can be minimized to some extent. Mutual trust between an organization and its employees can be created by several factors such as the design of the electrical system, the selection of electrical appliances, as well as the inspection and repairs [1]. Moreover, efficient modifications and improvements of the electrical switchboard controlling devices [2] can create acceptance of the devices and the organization.

Presently, the device used to control an electrical switchboard consists of a lowpressure system and a high-pressure system that are ready to use and manufactured domestically to be used in various types of work such as small-scale to large-scale industrial plants, condominiums, buildings, hotels, department stores, and hospitals [3,4]. Therefore, the ready-to-use switchboard controlling devices are not well suited to be thoroughly applied for all categories in every organization.

Several researchers have proposed a variety of energy-saving solutions efficient and suitable for various organizations and working conditions. In 2016, ref. [5] suggested a method to detect a malfunction in the operation of an electric circuit manually by the installation of an electrical meter through an electrical switchboard (ESB). However, the ESBs installed were incapable of processing and displaying information remotely. If malfunctions are not found in time, the cost of repairs and installation of the electrical system will be exorbitant. Subsequently, a study [6] suggested a more efficient process to inspect the electrical system by using a semi-automatic electrical control system. The mentioned process reduced the number of personnel needed for operation and the number of times needed for on-site inspection of the electrical system. It also reduced the severity of damages caused to electrical devices that can occur during power shortages and failure. Nevertheless, the aforementioned operation requires personnel to carry out an on-site inspection. Another study [7] offered an alternative solution to control the electrical power through statistical assessment for identifying changes in consumption methodology (SAICC). The solution involved using collected databases to function the operating time of the electrical equipment in advance. However, the setting and extrapolation of operation time may face errors due to in-depth miscalculations. Additionally, studies by [8,9] proposed another solution through a metropolitan-scale communication network to control involved electrical devices inside homes, in order to determine the workings and control of the devices. It functions automatically through an android application with the use of a long-range wide area network (LoRa) designed for connection support of low-power devices through the system of wide-area network (WAN). When compared with other solutions, the proposed solutions can be applied to the identification of operational statuses and control the devices accurately and automatically. Other than that, the study by [10] offered various methods to incorporate wireless technology such as the Zigbee protocol that can be connected wirelessly to control sensors for opening and closing doors. Further, they were applied to create a home automation system (HAS), which offers convenience and safety for the occupant of the house. Later, other studies [11,12] applied similar automation systems to control devices within buildings remotely and introduced a way to improve the power efficiency in smart buildings. Such systems can analyze and generate paths to conserve power, through manual selection of possible solutions available. For example, room lighting, ventilation, heating, and air conditioning system can be controlled through the screen panel of an electronic control system. Additionally, numerous researchers, e.g., [13-18] applied this technology to control power in a large number of smart homes. In addition, the authors of $[14,19]$ recommended a low-cost alternative to apply the technology, involving detection and monitoring power requirements and usage in households. Another study [20] also suggested a method to combine the technology of Zigbee protocol and the wireless fidelity (Wi-Fi) to overcome the limitations of software and hardware. It connects various devices through open source software, enabling control over selected devices to cooperate compatibly. The authors of [21] created a management system called the home energy management 
system (HEMS), through the use of open source software. HEMS connects electronic devices with other systems through an automated control system to achieve optimal power usage. Other aspects (e.g., thermal dissipation, electricity cost fluctuations throughout the day, and optimization of energy use in response to environmental variations) were taken into account.

From the methods mentioned above, there are a large number of researchers proposing various solutions to effectively control electricity power management devices. However, those methods were unable to achieve accuracy and efficiency in controlling the devices under different environments. Therefore, this research presents a way to increase efficiency in energy management and interconnected electrical devices' operations, through power switchboards operating in different environments. Additionally, the facility workers' opinions toward the proposed system were examined. This research investigated how multi-devices functioned in the same environment with the addition of a thermal sensor installed into the box of switchboards. The sensor creates convenience in inspecting, detecting, checking, and monitoring the electrical statuses in a real-time operating system, which enables the system to achieve accuracy and efficiency in controlling the devices, thereby preventing damages in advance and reducing power loss. The system can also be controlled remotely; the thermal sensor system contains SoC that enables communication with the application through a central command device. The contents of this research comprise five sections as follows: Section 2 indicates the system details of traditional electrical switchboards; Section 2 demonstrates the installation of the intranet-interconnected sensors to control the electrical switchboard remotely through internet connection; Section 3 demonstrates how to use the interconnected sensors through the application and Section 4 reveals the survey results of user acceptance and satisfaction of the system, and the results of the study, along with discussion, limitations of the research, and suggestions for future study.

\section{Analysis of the Traditional System and Presenting New Methods}

\subsection{System in Traditional Electrical Switchboards}

Management of traditional electrical switchboards is completed by personnel of the organization. An on-site inspection is performed weekly. Tasks include recording the operations of the electrical system such as measuring the heat of the busbar, inspecting the temperature of electrical devices in the electrical switchboard, checking the power meter, electric currents, and the voltages. This requires an expert human with a considerable amount of experience. Information received by current tools was analyzed through a prefabricated program to obtain viable information on statuses and created weekly, monthly, and yearly reports. Figure 1 shows examples of the electrical inspection tasks.

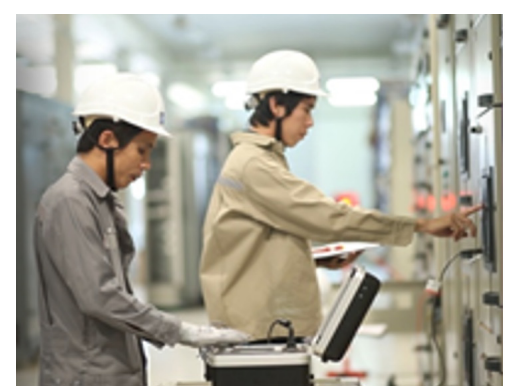

(a)

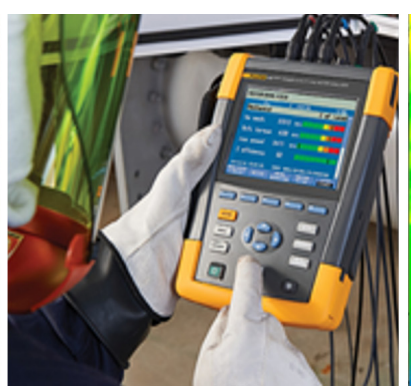

(b)

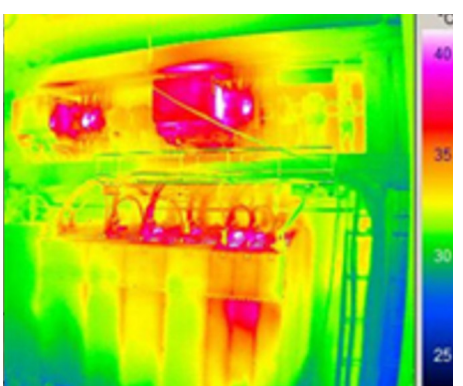

(c)

Figure 1. A display of status checks on electrical system: (a) heat checked by inspectors; (b) thermalimaging sensor technology temperature check; (c) display of the thermal temperature results, with green areas indicating low-temperature area and red areas indicating high temperature.

Based on Figure 1, the conventional monitoring and management of electrical switchboards are subject to limitations such as human resource management. The use of stateof-the-art temperature reporting instruments and temperature reading by the personnel 
leads to relatively high costs of inspection. In addition, if damages are not reported in time, they can cause severe harm to switchboards and result in a substantial amount of cost for damage repairs.

Figure 2 displays the damages incurred when statuses were not reported in time. Inspection of conventional electrical switchboards illustrates unpredictability and inability to pre-planned operations. Inability to properly plan maintenance of the electrical switchboard can also lead to equipment loss that renders in-competitiveness of the facility and is followed by future loss of competition in business, which further causes unsafety risks to personnel. A considerable amount of time has been spent on minimizing operational risks and maximize the ability to monitor the operation of electrical equipment $24 \mathrm{~h}$ a day by using manage electrical switchboards and intranet sensors systems.

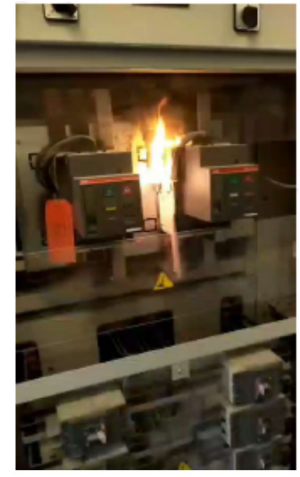

(a)

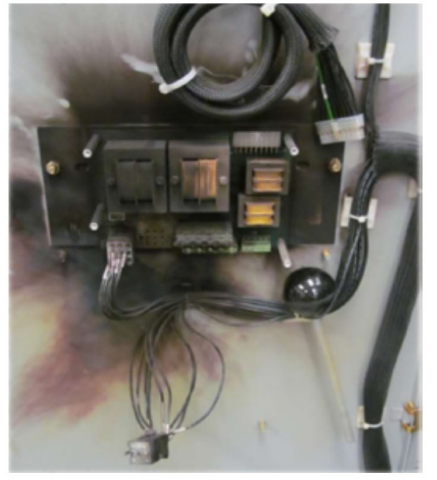

(b)

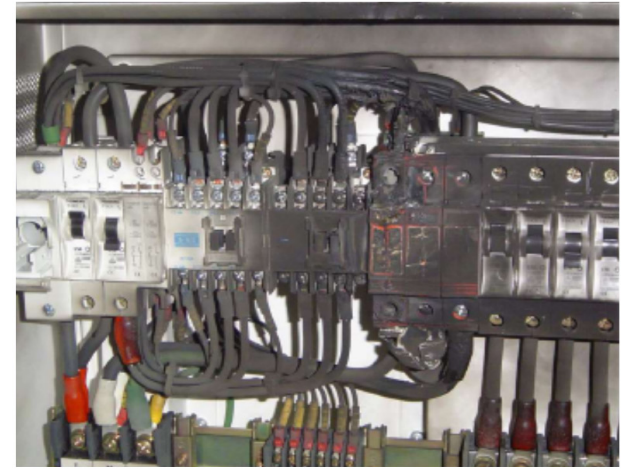

(c)

Figure 2. A display of electrical equipment damage caused by a short circuit: (a) a short circuit resulting in fire; (b) fire damage in equipment of a thunderstorm lightning protection system; (c) damages on the editing equipment caused by fire.

\subsection{Electrical Switchboard Control System Using Intranet Sensors Technology}

The authors studied relevant research and questionnaires on the experiences of system engineers, electrical engineers, and systems designers. Numerous experiences from experts in electrical safety inspections were taken into account. The conclusion of questionnaire results indicates that an application of an intranet sensors system can control various electrical equipment effectively. It can control an electrical system in smart homes, a remote traffic light system, a facility anti-theft system, as well as an industrial electrical power control system. This example inspired the authors to take advantage of the intranet-based technology that can be applied to control the electrical system in the switchboard through an internet connection, as shown in Figure 3.
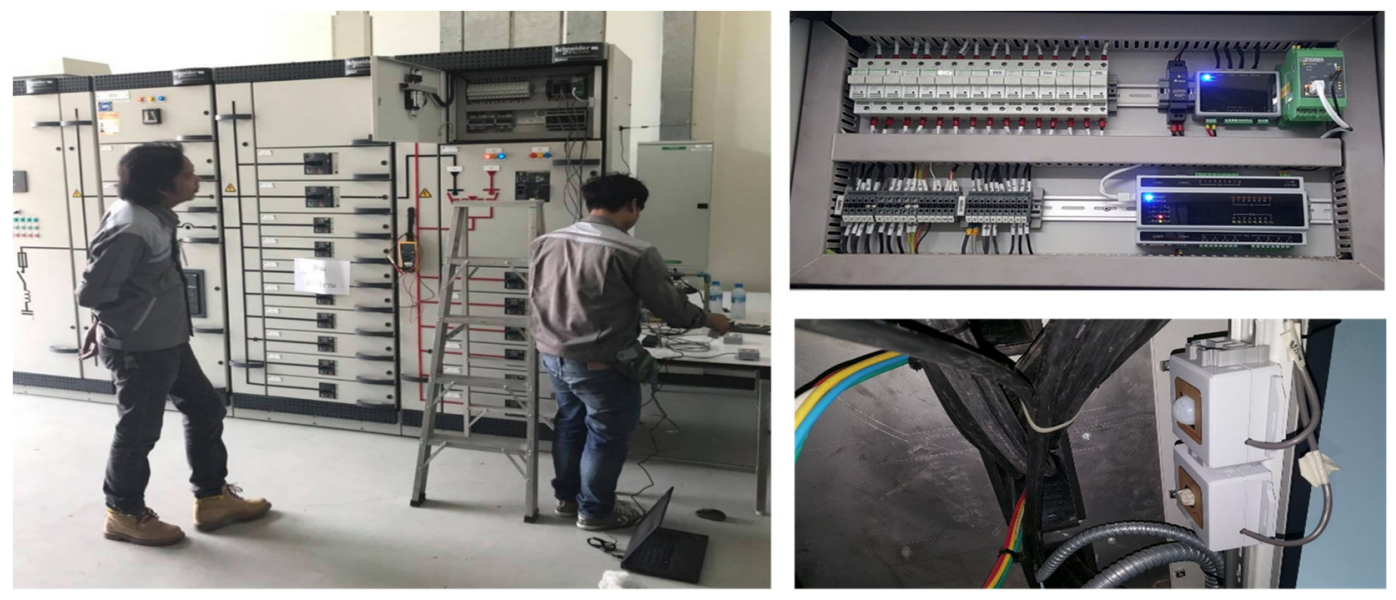

Figure 3. A display of an intranet sensors system installment in various electrical switchboard settings. 
Figure 3 shows the installments of the intranet sensors system in various electrical switchboard settings, while Figure 4 presents its architecture framework and installation in an electric structure. After being installed, electronic devices linked to communicate with each other through local intranet networks will yield the system the following benefits: First, it enables the control and connectivity of various electronic devices through the local intranet when the temperature is over a certain level. Second, the system can measure and report the humidity level inside the switchboard to prevent having a relative humidity level higher than the specified standard. Third, it can detect the amount of smoke to prevent a fire initiation within the electrical switchboard. Additionally, it includes an automatic alarm system to the fire extinguisher to put out the fire automatically. Fourth, it can detect the movement of objects or persons to notify the operator about the events. Fifth, it can record the numbers of lightning strikes from thunderstorms and make plans to purchase additional safety equipment in a timely manner. Sixth, it can analyze electricity consumption simultaneously with a digital electric meter and be able to record voltages, electric power, and electrical units to display different forms of electrical energy usage. Seventh, and lastly, it can remotely control the electrical connecting to the internet with connected devices such as smartphones and laptops. Unlike semiconductor chips in the past that electronic devices can only transmit and display information, this innovative system can monitor and report the status of the electrical switchboard system and measure the temperature of a device with the highest electrical current flow. As soon as the equipment junction point is at risk, alarms can be signaled in the real-time operating system through the operator's smart devices such as smartphones, laptops, and desktop stations. The reported results of electric switchboard alarms are displayed in Figure 5.

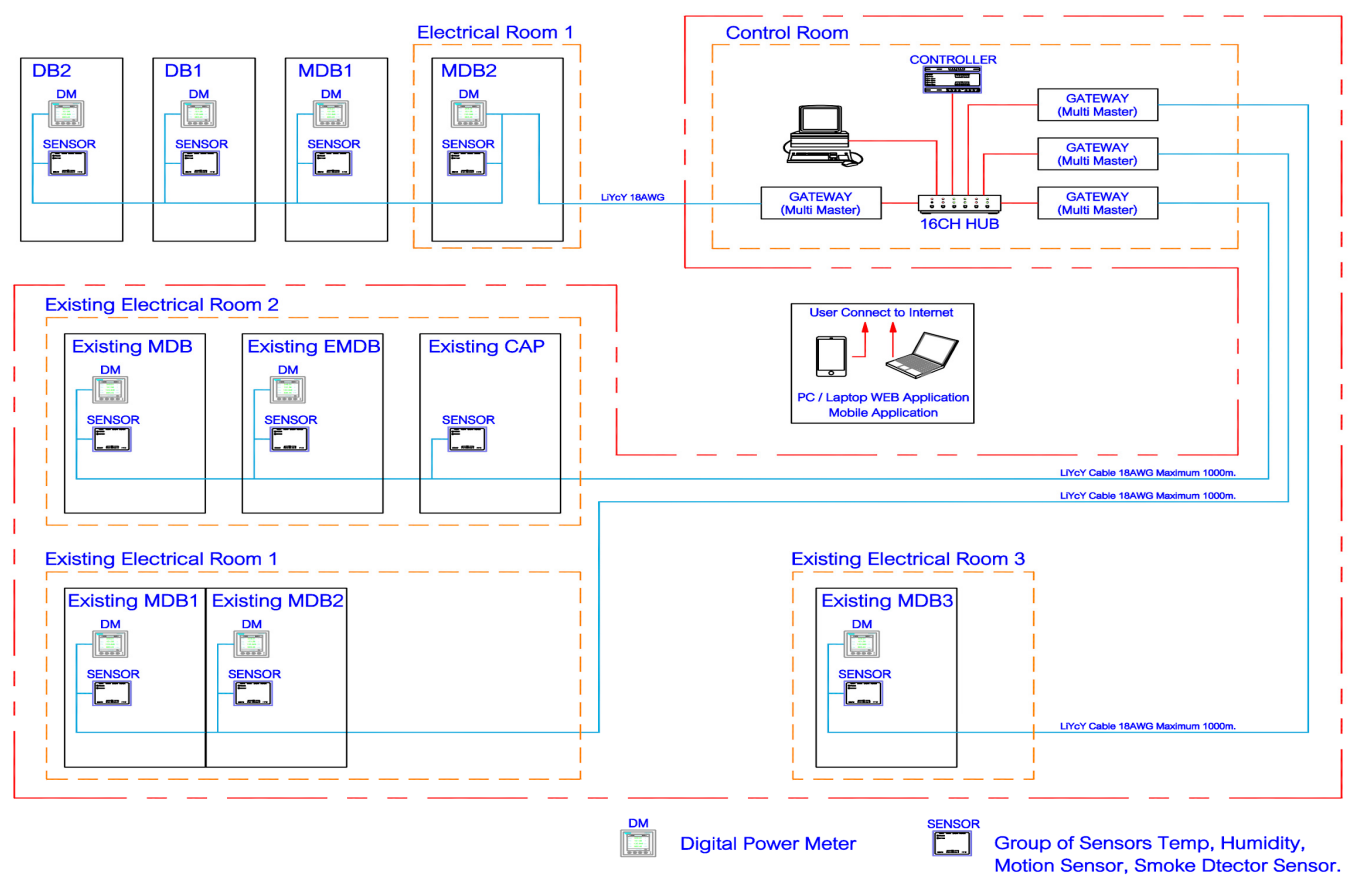

Figure 4. Display of the intranet sensors system architecture and installation in an electrical structure. 


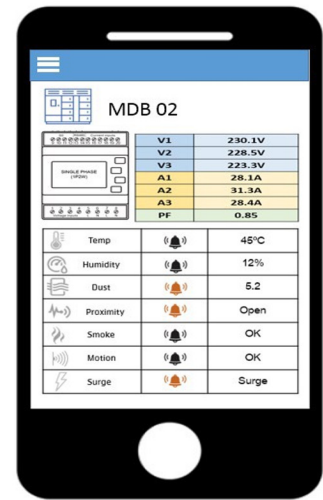

(a)

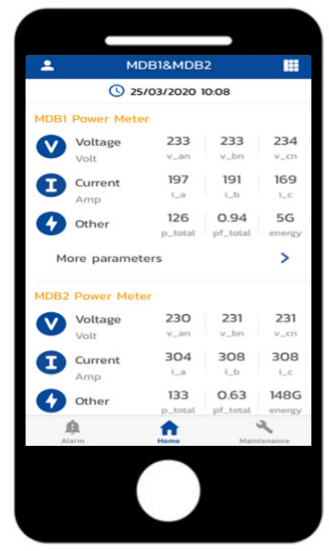

(e)

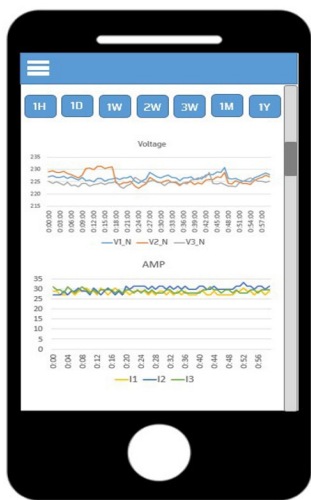

(b)

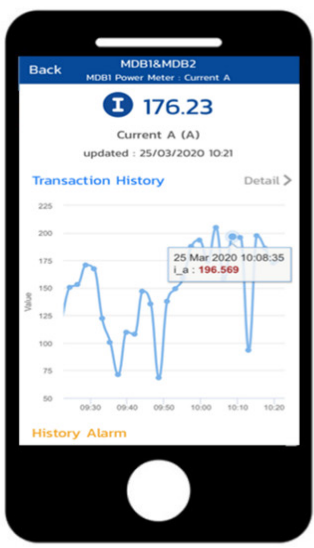

(f)

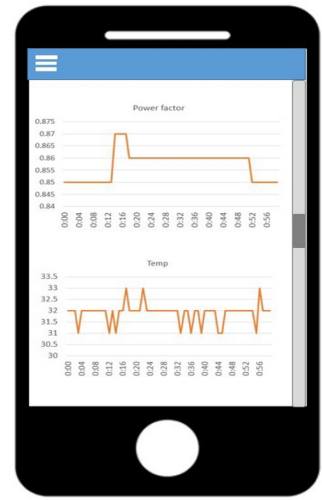

(c)

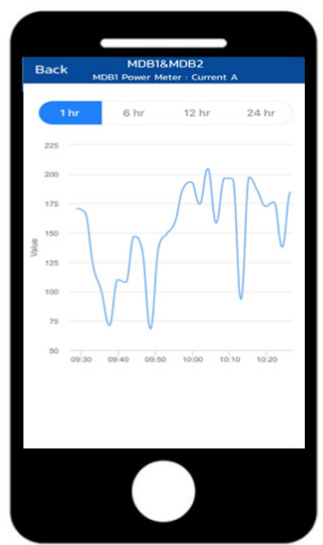

(g)

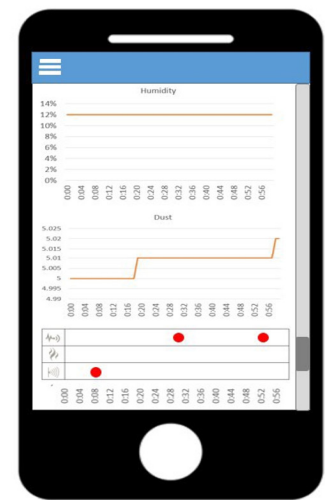

(d)

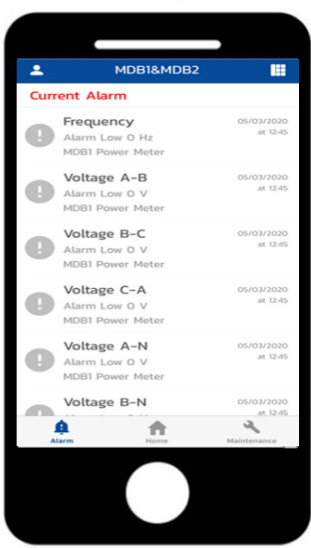

(h)

Figure 5. Display of the results via a smartphone device to control an electric switchboard, consisting of (a) various system notification settings, (b) the amount of electricity consumption, (c) the current electric power and temperature, (d) the amount of humidity inside the switchboard, (e) power quality and related parameters, (f) power quality and parameters in graph model, (g) graphs reporting the past $24 \mathrm{~h}$ of electricity consumption, and (h) electrical fault warning area in the switchboard.

\section{Methodology \\ 3.1. Data Collection}

This research aimed to measure the efficiency and acceptance of intranet sensors systems for usage with electrical switchboards management. Through purposive sampling, 300 expert employees were sorted into operators and technicians, from 3 companies (including 92 people from Asefa Public Company Limited, 110 people from WHA Bangna Business Complex and WHA Group, and 98 people Carabao Group PCL).

\subsection{Creation of Research Tools}

A five-scale questionnaire was designed for the assessment of efficiency and acceptance of the introduced intranet sensors system. The assessment was detailed as follows:

The evaluation of personnel management efficiency and electrical switchboards management was divided into a 5-level scale as follows: highest efficiency level (5 points), high-efficiency level (4 points), medium-efficiency level (3 points), low-efficiency level (2 points), and the lowest efficiency level (1 score). The mean values for variable priorities and feedback levels from participants were applied for assessing user opinions of performance. The ranges of feedback were ranked from the highest to the lowest as follows: (1) highest efficiency level (average between 4.51 and 5.00 points); (2) high-efficiency level (average between 3.51 and 4.50 points); (3) moderate-efficiency level (average between 2.51-3.50 points); (4) low-efficiency level (average between 1.51 and 2.50 points); (5) the lowest efficiency level (average between 1.00 and 1.50 points), respectively. 
The evaluation of the acceptance of intranet sensors system in managing electrical switchboards was divided into a 5-level scale as follows: the highest level (5 points), high level (4 points), moderate level (3 points), low level (2 points), and the lowest level (1 point). Next, mean values were calculated in order to sort the variables and feedback from participants. The levels include the highest level of acceptance (average between 4.51 and 5.00 points), high level of acceptance (average between 3.51 and 4.50 points), moderate level of acceptance (average between 2.51 and 3.50 points), low level of acceptance (average between 1.51 and 2.50 points), and the lowest level of acceptance (average between 1.00 and 1.50 points).

\subsection{Data Analysis and Interpretation}

The analysis and interpretation followed the procedures below.

First, the researcher tested the accuracy of the data obtained from the questionnaires via the approval of five experts. All questionnaires were tested for accuracy and consistency with respect to the research objectives. Questionnaires obtained a score number greater than 0.5 from an index of item-objective congruence (IOC). All 21 questions in the questionnaires had an IOC of 0.60-1.00. This indicated that questionnaires were eligible for research. Additionally, each question of the questionnaire was measured for the discriminant power by using techniques to find the correlation between questions or item-total correlation. The item-total correlation's value for the questionnaire on the effectiveness of the entire system was between 0.673 and 0.862 , and the correlation value for the intranet sensors system acceptance was between 0.661 and 0.885 .

In the second step, the researchers carried out a reliability test using the alpha coefficient based on Cronbach's theory [22]. The reliability of the Intranet Sensors System's efficiency in the management of electrical switchboards obtained an alpha coefficient value of 0.982 and the confidence in the intranet sensors system obtained an alpha coefficient between 0.981 and 0.982 . This agrees with the theory of [23] that states a confidence factor of more than 0.70 , suggesting that the questionnaire had a quality that can be used to collect data for research purposes.

In the third step, the composition analysis of questionnaires was carried out by using statistical analysis and oblique rotation through the varimax method. This is a method for examining the elements of the variable, by mixing the smallest variable with the highest correlation. The rotation is to check whether the variables that are on the same side are related to each other and that all elements are true representations. The analysis yielded three components, in which it was found that the grouping of variables in each element was more evident. Above all, every variable in each component had a weight of more than 0.30. Additionally, the component criteria in communality value were greater than 0.5. Lastly, the eigenvalue or the fluctuation of all variables in each component was greater than 1.00, and the factor-loading value, a value indicating the relationship between the variable and the element, was more than 0.30 . It can be concluded that all variables could be placed into the components of the levels of efficiency and acceptance of the intranet sensors system in the management of electrical switchboard panels in accordance with the theory of [24].

Verifying the suitability of the data from the analysis resulted in the construction of questionnaires, each of which had a relationship between the variables and the elements for efficiency and acceptance of the Intranet Sensors System in the management of electrical switchboards. It was found that the Kaiser-Meyer-Olkin (KMO) value was 0.970, Bartlett's test of sphericity had the statistical significance value ( $p$-value) of 0.000 , which is less than 0.05 , suggesting that all data analysis of the 3 components and 21 variables were valid. 


\subsection{Statistics Used in Research}

In this research, descriptive and inferential statistics were used to analyze the opinions of the internet's efficiency and acceptance in the management of electrical switchboards using mean and standard deviation as defined in Equations (1) and (2).

$$
\begin{gathered}
\bar{X}=\frac{\sum X}{N} \\
\text { S.D }=\frac{\sqrt{\sum(\mathrm{x}-\overline{\mathrm{x}})}}{(\mathrm{N})}
\end{gathered}
$$

where $\bar{x}$ is the mean of the score, and SD is the standard deviation, $x$ is the assessed score from the involved participants. $N$ is the number of participants, and $\bar{x}$ is the sum of the evaluation scores.

The results of the intranet sensors system acceptance of efficiency are presented below.

From Table 1, the results revealed that the efficiency of the intranet sensors system by the electrical switchboard technician had a high-level score $(\bar{x}=4.13 ; \mathrm{SD}=0.696)$. When considering individual categories, the efficiency was at a high level in every category. The results can be sorted by the average, ranging from the smallest to the greatest. The first three in a top-down manner are as follows: (1) ability to record values of various functions of the device and generate graphs to observe changes or to identify malfunction devices effectively; (2) ability to support and make decisions in an operation, along with a notification system via SMS and e-mail to the administrator or project owner in industrial plants, buildings, and businesses ( $\overline{\mathrm{x}}=4.17$; $\mathrm{SD}=0.784)$; (3) ability to capture operational images and send alerts via the application efficiently $(\bar{x}=4.17 ; \mathrm{SD}=0.831)$, respectively.

Table 1. Acceptance test results of intranet sensors system efficiency.

\begin{tabular}{lccc}
\hline \multicolumn{1}{c}{ Efficiency of the Intranet Sensors System } & $-\overline{\mathbf{x}}$ & SD & Efficiency Level \\
\hline $\begin{array}{l}\text { 1. The system is beneficial to the business } \\
\text { owner, administrator, and project owner in } \\
\text { industrial plants, buildings, and businesses. }\end{array}$ & 4.13 & 0.800 & High \\
\hline $\begin{array}{l}\text { 2. The system is able to support the operation } \\
\text { and decision making of the work, along with } \\
\text { a notification system via SMS and e-mail to } \\
\text { the administrator and project owner in } \\
\text { industrial plants and businesses. }\end{array}$ & 4.17 & 0.784 & High \\
\hline $\begin{array}{l}\text { 3. The system is able to manage materials and } \\
\text { equipment for changes and repairs that will } \\
\text { be used in the future. }\end{array}$ & 4.09 & 0.847 & High \\
\hline $\begin{array}{l}\text { 4. The system is more efficient than } \\
\text { traditional systems that rely on the experience } \\
\text { of the operator in determining malfunction } \\
\text { from electrical switchboard alarm systems. }\end{array}$ & 4.12 & 0.827 & High \\
\hline $\begin{array}{l}\text { 5. The system designs functionality and } \\
\text { implementation of information to process } \\
\text { data and report results from the } \\
\text { system quickly. }\end{array}$ & 4.09 & 0.867 & High \\
\hline $\begin{array}{l}\text { 6. The system is able to collect the operating } \\
\text { parameters of the equipment and create } \\
\text { graphs to observe changes or identify } \\
\text { malfunctions effectively. }\end{array}$ & 4.21 & 0.830 & High \\
\hline
\end{tabular}


Table 1. Cont.

\begin{tabular}{lccc}
\hline \multicolumn{1}{c}{ Efficiency of the Intranet Sensors System } & $\overline{\mathbf{x}}$ & SD & Efficiency Level \\
\hline $\begin{array}{l}\text { 7. The system effectively captures operational } \\
\text { images that can send alerts through } \\
\text { the application. }\end{array}$ & 4.17 & 0.831 & High \\
$\begin{array}{l}\text { 8. The system is reliable in the stability and } \\
\text { effective operations on switchboards. }\end{array}$ & 4.05 & 0.816 & High \\
$\begin{array}{l}\text { 9. The system creates confidence and safety in } \\
\text { electrical systems in factories, buildings, } \\
\text { and businesses. }\end{array}$ & 4.15 & 0.841 & High \\
\hline \begin{tabular}{l} 
Total \\
\hline
\end{tabular} & 4.13 & 0.696 & High \\
\hline
\end{tabular}

As evident from Table 2, the users of electrical switchboards had high opinions of overall intranet sensors system acceptance $(\bar{x}=4.00 ; S D=0.662)$, and regarding the mean of the entire section, the acceptance level was high. The results can be sorted by the average, ranging from the smallest to the greatest. The first three descending order are as follows: (1) comparative benefit $(\overline{\mathrm{x}}=4.13 ; \mathrm{SD}=0.703)$; (2) observable aspect $(\overline{\mathrm{x}}=4.04 ; \mathrm{SD}=0.744)$; (3) testable aspect $(\bar{x}=3.98 ; \mathrm{SD}=0.728)$, respectively.

Table 2. Analysis of feedback on the acceptance of internet applications for the management of electrical switchboards.

\begin{tabular}{lccc}
\hline \multicolumn{1}{c}{ Acceptance of Intranet Sensors System } & $\overline{\mathbf{x}}$ & SD & Acceptance Level \\
\hline 1. Relative advantage & 4.13 & 0.703 & High \\
\hline $\begin{array}{l}\text { 2. Compatibility with existing systems in } \\
\text { factories, buildings, and businesses }\end{array}$ & 3.98 & 0.737 & High \\
\hline 3. Complexity in operation & 3.87 & 0.760 & High \\
\hline 4. Trainability & 3.98 & 0.728 & High \\
\hline 5. Observability & 4.04 & 0.744 & High \\
\hline Total & 4.00 & 0.662 & High \\
\hline
\end{tabular}

As indicated in Table 3, the results of composition analysis according to spindle rotation with the varimax method yield the three most relevant components, consisting of component 1 (efficiency in usefulness in managing services and building confidence in the electrical system (EITORA)), component 2 (usage and management within the system (CPTTOT)), and component 3 (usage and management within the system $(\mathrm{CT})$ ), respectively.

Table 3. Results of composition analysis of intranet sensors system efficiency and acceptance for electrical switchboard management.

\begin{tabular}{clccc}
\hline Component & \multicolumn{1}{c}{ Name of Component } & Eigenvalues & Percentage of Variance & $\begin{array}{c}\text { Percentage of } \\
\text { Cumulative Variance }\end{array}$ \\
\hline 1 & $\begin{array}{l}\text { Efficiency in usefulness in } \\
\text { managing services and building } \\
\text { confidence in the electrical system } \\
\text { (EITORA) } \\
\text { Usage and management within } \\
\text { the system (CPTTOT) } \\
\text { Integration and implementation } \\
\text { with the electrical switchboard } \\
\text { management plan (CT) }\end{array}$ & 18.327 & 61.092 & 6.092 \\
\hline 3 & 1.050 & 3.500 & 70.201 \\
\hline
\end{tabular}


From Table 4, it can be seen that the composition analysis of efficiency and acceptance of intranet sensors system in the management of electrical switchboards from all variables yielded a weight value greater than 0.30 for all variables. Therefore, it can be concluded that all the variables under investigation could be placed in the components of the intranet sensors system efficiency and acceptance in the management of electrical switchboards.

Table 4. Results of composition analysis of efficiency and acceptance of intranet sensors system in electrical switchboard management.

\begin{tabular}{|c|c|c|}
\hline & $\begin{array}{l}\text { Composition Analysis of Efficiency and Acceptance of Intranet } \\
\text { Sensors System in Electrical Switchboard Management }\end{array}$ & $\begin{array}{l}\text { Component } \\
\text { Weight }\end{array}$ \\
\hline \multicolumn{3}{|c|}{$\begin{array}{l}\text { Efficiency in Usefulness in Managing Services and Building Confidence in the } \\
\text { Electrical System (EITORA) }\end{array}$} \\
\hline EITO1 & Beneficial to all businesses and sectors & 0.733 \\
\hline EITO5 & Accepted by the users in every step & 0.758 \\
\hline EITO4 & Management being based on operator expertise & 0.755 \\
\hline EITO6 & Ability to store operating values of the device & 0.749 \\
\hline EITO2 & Able to support and make decisions in an operation & 0.739 \\
\hline EITO3 & Able to manage materials and equipment & 0.706 \\
\hline RA1 & Directly beneficial to the management of electrical switchboards & 0.704 \\
\hline EITO7 & Able to record operational images and send alert messages & 0.698 \\
\hline RA2 & System resulting in more efficient management & 0.685 \\
\hline RA3 & System allowing effective decision support & 0.652 \\
\hline EITO9 & System building reliability and safety & 0.615 \\
\hline RA4 & System performing a good inspection of the electrical switchboard. & 0.594 \\
\hline EITO8 & System being reliable and stable & 0.587 \\
\hline RA5 & $\begin{array}{l}\text { System being useful to the development plan of electrical } \\
\text { switchboard management }\end{array}$ & 0.571 \\
\hline \multicolumn{3}{|c|}{ Usage and management within the system (CPTTOT) } \\
\hline $\mathrm{CP} 3$ & Personnel involved having a good understanding of the system & 0.740 \\
\hline TT4 & System being tested part by part & 0.736 \\
\hline TT1 & Ability to perform a trial run before installing & 0.730 \\
\hline $\mathrm{CP} 2$ & Operation of the system being not complex & 0.720 \\
\hline TT3 & Trial run of the system revealing the overall operation of the system. & 0.703 \\
\hline OT2 & System designed to meet the needs of the users & 0.684 \\
\hline TT2 & Errors from the trial having no effect on the operation & 0.680 \\
\hline OT1 & Results from the operation of the system being clear and accurate & 0.666 \\
\hline $\mathrm{CP} 1$ & System being easy to operate & 0.653 \\
\hline OT3 & System reflecting the overall management of the electrical switchboard & 0.629 \\
\hline OT4 & System being a safe innovation, affecting trust & 0.578 \\
\hline \multicolumn{3}{|c|}{ Component 3 Integration and implementation with the electrical switchboard management plan (CT) } \\
\hline $\mathrm{CT} 4$ & Ability to be integrated with future management plans & 0.726 \\
\hline CT1 & Ability to be integrated with a traditional management system & 0.704 \\
\hline CT5 & Ability to respond well to the policy of the agency & 0.679 \\
\hline СТ3 & No effects on and conflicts in decision making & 0.659 \\
\hline $\mathrm{CT} 2$ & $\begin{array}{l}\text { Ability to be built upon the traditional management depending on } \\
\text { individual skills }\end{array}$ & 0.610 \\
\hline
\end{tabular}

As shown in Table 5, analysis on structural precision had the construct reliability value greater than 0.6 for all components and discriminant accuracy with average variance extracted greater than 0.5 in all variables. In addition, the chi-squared statistic equaled 
823.279 , and the chi-squared statistic divided by degree of freedom with the value of 351 yielded a value of 2.345 (acceptable value is 2). The root-mean-square error of approximation (RMSEA) was 0.056, and the Tucker-Lewis index (TLI) value was 0.952. Therefore, all the values of the intranet sensors system in electrical switchboard management were clearly agreeable in accordance with the data and can be presented in the model for further analysis for confirmation, as shown in Figure 6.

Table 5. The inspection of the discriminant validity and construct validity.

\begin{tabular}{clcc}
\hline Component & \multicolumn{1}{c}{ Name of Component } & CR & AVE \\
\hline 1 & $\begin{array}{l}\text { Efficiency in usefulness in managing services and } \\
\text { building confidence in the electrical system } \\
\text { (EITORA) }\end{array}$ & 0.962 & 0.646 \\
\hline 2 & $\begin{array}{l}\text { Usage and management within the system } \\
\text { (CPTTOT) }\end{array}$ & 0.954 & 0.650 \\
\hline 3 & $\begin{array}{l}\text { Integration and implementation with the } \\
\text { electrical switchboard management plan (CT) }\end{array}$ & 0.916 & 0.687 \\
\hline
\end{tabular}

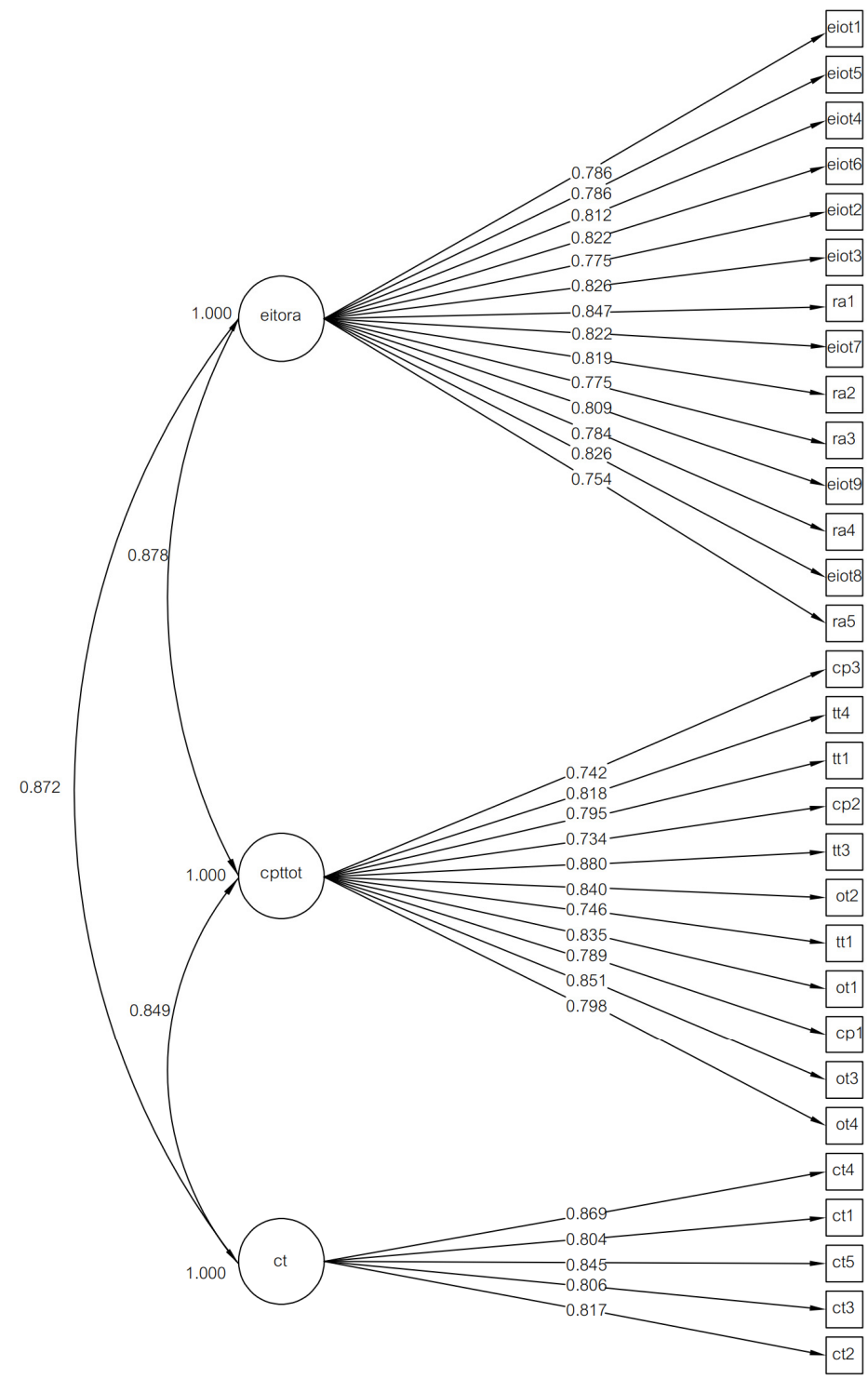

Figure 6. Analysis model for the composition of each variable. 
Figure 6 shows that overall opinions on the efficiency of the intranet sensors system were high in all categories $(\bar{x}=4.13 ; \mathrm{SD}=0.696)$. By sorting the average from descending order, the first top three ranks were as follows: (1) being able to store various values of the device, generate graphs to observe changes, and detect malfunctions effectively; $(\bar{x}=4.21 ; \mathrm{SD}=0.830) ;(2)$ being able to support and make decisions in an operation, along with a notification system via SMS and email to the administrator or project owner in industrial plants, workers in buildings, and businesses ( $\bar{x}=4.17$; $\mathrm{SD}=0.784)$; (3) being able to effectively capture operational images that can send alerts through the application $(\bar{x}=4.17 ; \mathrm{SD}=0.831)$. Considering the acceptance of the intranet sensors system, the overall average was high $(\overline{\mathrm{x}}=4.00 ; \mathrm{SD}=0.662)$. By sorting the average from descending order, the first three ranks were as follows: (1) comparative benefit $(\bar{x}=4.13$; $S D=0.703$ ); (2) the model, efficiency, and acceptance of convenience in the inspection of electrical switchboards within factories, buildings, and businesses ( $\overline{\mathrm{x}}=4.17$; $\mathrm{SD}=0.805)$; (3) the benefits to the development plan of electrical switchboard management for greater safety. This indicated confidence in the electrical system with values of $\bar{x}=4.15$ and $S D=0.833$. Moreover, the system allowed the management of electrical switchboards in factories, buildings, and businesses to process background information to support effective decision making $(\bar{x}=4.13 ; \mathrm{SD}=0.791)$. On observability $(\overline{\mathrm{x}}=4.04 ; \mathrm{SD}=0.744)$, the system was able to reflect the overall management efficiency of the electrical switchboard ( $\bar{x}=4.07$; $\mathrm{SD}=0.849)$. Specifically, the system is an innovation that increases the safety, security, and reliability of electrical systems in factories, buildings, and businesses $(\bar{x}=4.07 ; \mathrm{SD}=0.871)$. The system was able to be designed to meet the needs of the users $(\bar{x}=4.04 ; \mathrm{SD}=0.803)$. On trainability, the system was able to reflect trainability $(\bar{x}=3.98 ; \mathrm{SD}=0.728)$. Specifically, the system revealed the overall operation of the system $(\bar{x}=4.05 ; \mathrm{SD}=0.804)$, the ability to perform a trial run before installing $(\overline{\mathrm{x}}=4.01 ; \mathrm{SD}=0.818)$, and the ability to test individual parts of the developed system $(\overline{\mathrm{x}}=3.98 ; \mathrm{SD}=0.7803)$.

\section{Conclusions and Future Work}

\subsection{Conclusions}

Drawing upon the aforementioned results of the study, it could be concluded that electrical switchboard users have very high opinions of the overall performance of the intranet sensors system. It can store values for various functions and generate graphs to observe changes and effectively detect malfunctions. It enables operation support of decision making on the tasks needed to be accomplished efficiently, along with notification system via SMS and e-mail to the administrator and project owner in industrial plants and businesses. Additionally, the intranet sensors system installed on electrical switchboards can effectively record operational images and send alert messages. The value of the acceptance of the intranet sensors system was high. It directly benefits the job of management of electrical switchboards in factories, buildings, and businesses. It can be a basis in decision making and create convenience for inspection, benefiting the development plan of electrical switchboard management. It also creates more safety for personnel. The results from the operation of the system are accurate and clear, and the design of the system also meets personnel needs. It can be considered as an innovative system that can effectively increase safety and devices stability. It also creates trust among workers within the management realm in industrial plants, buildings, and businesses. As for the actual trial, the developed system was designed to be able to perform trial runs in individual parts, which are carried out to reduce errors caused by experiments, and errors from the trial runs do not affect the overall operation of the original electrical switchboard system.

\subsection{Suggestions for Future Research}

1. Researchers may need to study and collect additional information in other areas such as price and break-even points to be considered in the decision making of small-scale entrepreneurs who use electrical switchboards to compare the system insights. This is because none of the small-scale projects have been implemented yet. 
2. The installation of various hardware systems or sensors must be adjusted according to the electrical system of the factory and building. Its establishment makes the installation of equipment in the appropriate position convenient.

3. Control of electrical equipment through applications may encounter an unstable connection problem due to the device being located inside the electrical switchboard in a position where the original Wi-Fi signal. Therefore, an additional signal diffuser needs to be installed.

Author Contributions: Conceptualization, S.C. and K.W.; data curation, S.C.; formal analysis, S.C. and K.W.; funding acquisition, S.C.; project administration, S.C. and K.W.; software analysis, S.C. and K.W.; supervision, S.C.; writing-original draft preparation, S.C. and K.W.; and writing-review and editing, S.C. and K.W. All authors have read and agreed to the published version of the manuscript.

Funding: This research was financially supported by Mahasarakham Business School, Mahasarakham University, Thailand.

Institutional Review Board Statement: Not applicable.

Informed Consent Statement: Not applicable.

Data Availability Statement: Not applicable.

Acknowledgments: This research was financially supported by Mahasarakham Business School, Mahasarakham University, Thailand. The authors would like to thank Worawat Sa-ngiamvibool, Thailand, for data analysis and help in the preparation of the original draft for this work. Finally, the authors also thank Intisarn Chaiyasuk for his English language consulting time and proofreading the whole paper.

Conflicts of Interest: The authors declare no conflict of interest.

\section{References}

1. Aleksander, F.; Subgatullin, B.; Ahmed, Y.E. Methods of electrical loads calculation and selection of electrical power equipment. In Proceedings of the International Conference on Electrotechnical Complexes and Systems (ICOECS), Ufa, Russia, 21-25 October 2019.

2. Edwin, L.; Goodno, B.J.; Craig, J.I. Development of a Method to Generate a Simplified Finite Element Model for an Electrical Switchboard Cabinet. In Proceedings of the International Specialty Conference on Cold-Formed Steel Structures, Baltimore, MD, USA, 10 November 2016; pp. 837-852.

3. Clemente, K. Two application case studies of short switchboards in obstructed electrical rooms. In Proceedings of the 2018 IEEE/IAS 54th Industrial and Commercial Power Systems Technical Conference (I\&CPS), Niagara Falls, ON, Canada, 7-10 May 2018; pp. 1-8.

4. Saikovski, V. Predicting the results of the application of innovations of electrical systems in buildings with the help of a simple model. In Proceedings of the 2017 6th International Youth Conference on Energy (IYCE), Budapest, Hungary, 21-24 June 2017; pp. 1-6.

5. Mendes, L.R.; Wazen, R.N. Implementation of predictive maintenance in thermography in panels power substations, Portu-guese. J. Eng. Technol. 2016, 8, 91-102.

6. Huda, A.N.; Taib, S. Application of infrared thermography for predictive/preventive maintenance of thermal defect in electrical equipment. Appl. Therm. Eng. 2013, 61, 220-227. [CrossRef]

7. Xavier, S.G.; Escrivá, G.E.; Blay, C.R. Statistical methodology to assess changes in the electrical consumption profile of build-ings. Energy Build. 2018, 164, 99-108.

8. Islam, R.; Rahman, W.; Rubaiat, R.; Hasan, M.; Reza, M.; Rahman, M.M. LoRa and server-based home automation using the internet of things (IoT). J. King Saud Univ. Comput. Inf. Sci. 2021, 1-10. [CrossRef]

9. Bababe, A.B.; Ashish, K.J.; Kumar, R. Lora Based Intelligent Home Automation System. Int. J. Eng. Adv. Technol. 2017, 6, 88-92.

10. Nedelcu, A.-V.; Sandu, F.; Machedon-Pisu, M.; Alexandru, M.; Ogrutan, P. Wireless-based remote monitoring and control of intelligent buildings. In Proceedings of the 2009 IEEE International Workshop on Robotic and Sensors Environments, Lecco, Italy, 6-7 November 2009; pp. 47-52. [CrossRef]

11. Fernández-Caramés, T.M. An Intelligent Power Outlet System for the Smart Home of the Internet of Things. Int. J. Distrib. Sens. Netw. 2015, 11, 1-11. [CrossRef] [PubMed]

12. Farias, C.; Pirmez, L.; Delicato, F.C.; Soares, H.; Santos, I.L.D.; Carmo, L.F.R.C. A control and decision system for smart buildings. In Proceedings of the IEEE 10th International Conference on Ubiquitous Intelligence, Sorrento Peninsula, Italy, 18-21 December 2013; pp. 256-261. 
13. Wenbo, Y.; Quanyu, W.; Zhenwei, G. Smart home implementation based on Internet and WiFi technology. In Proceedings of the 2015 34th Chinese Control Conference (CCC), Hangzhou, China, 28-30 July 2015; pp. 9072-9077.

14. Bhatt, A.; Patoliya, J. Cost effective digitization of home appliances for home automation with low-power WiFi devices. In Proceedings of the 2016 2nd International Conference on Advances in Electrical, Electronics, Information, Communication and Bio-Informatics (AEEICB), Chennai, India, 27-28 February 2016; pp. 643-648.

15. Li, Z.; Song, M.; Gao, L.D. Design of Smart Home System Basedon ZigBee. Appl. Mech. Mater. 2014, 635-637, 1086-1089.

16. Cruz-S'Nchez, H.; Havet, L.; Chehaider, M.; Song, Y.-Q. MPIGate: A Solution to Use Heterogeneous Networks for Assisted Living Applications. In Proceedings of the 2012 9th International Conference on Ubiquitous Intelligence and Computing and 9th International Conference on Autonomic and Trusted Computing, Fukuoka, Japan, 4-7 September 2012; pp. $104-111$.

17. Huang, F.-L.; Tseng, S.-Y. Predictable smart home system integrated with heterogeneous network and cloud computing. In Proceedings of the 2016 International Conference on Machine Learning and Cybernetics (ICMLC), Jeju, Korea, 10-13 July 2016; Volume 2, pp. 649-653.

18. Vivek, G.; Sunil, M. Enabling IOT services using WIFI-ZigBee gateway for a home automation system. In Proceedings of the 2015 IEEE International Conference on Research in Computational Intelligence and Communication Networks (ICRCICN), Kolkata, India, 20-22 November 2015; pp. 77-80.

19. Kodali, R.K.; Soratkal, S. MQTT based home automation system using ESP8266. In Proceedings of the 2016 IEEE Region 10 Humanitarian Technology Conference (R10-HTC), Agra, India, 21-23 December 2016; pp. 1-5.

20. Froiz-Míguez, I.; Fernández-Caramés, T.M.; Fraga-Lamas, P.; Castedo, L. Design, Implementation and Practical Evaluation of an IoT Home Automation System for Fog Computing Applications Based on MQTT and ZigBee-WiFi Sensor Nodes. Sensors 2018, 18, 2660. [CrossRef] [PubMed]

21. Iqbal, J.; Khan, M.; Talha, M.; Farman, H.; Jan, B.; Muhammad, A.; Khattak, H.A. A generic internet of things architecture for controlling electrical energy consumption in smart homes. Sustain. Cities Soc. 2018, 43, 443-450. [CrossRef]

22. Cronbach, L. Essentials of Psychological Testing, 3rd ed.; Harper \& Row: New York, NY, USA, 1970.

23. Hair, J.F.; Black, W.C.; Alderson, R.E. Multivarible Data Analysis, 6th ed.; Pearson Prentice Hall: Upper Saddle River, NJ, USA, 2006.

24. Hair, J.F.; Anderson, R.E.; Tatham, R.L.; Black, W.C. Multivariate Data Analysis, 5th ed.; Prentice Hall: Upper Saddle River, NJ, USA, 1998. 